\title{
Increase in testosterone sensitivity induced by constant light in relation to melatonin injections in rats
}

\author{
T. Porkka-Heiskanen, M-L. Laakso, D. Stenberg, A. Alila and G. Johansson \\ Department of Physiology, University of Helsinki, Finland
}

\begin{abstract}
Summary. In this experiment we investigated whether the lack of the nocturnal melatonin peak under constant light would cause an increase in testosterone sensitivity. Castrated rats were kept under periodic or constant light for one week. They received a daily injection of vehicle, testosterone propionate $(125 \mu \mathrm{g})$, melatonin $(50 \mu \mathrm{g})$ or testosterone plus melatonin $(125 \mu \mathrm{g}+50 \mu \mathrm{g})$. Serum and pituitary gonadotrophins and pineal melatonin were measured at the end of the experiment. Under constant light, testosterone injections reduced the serum luteinizing hormone concentration in castrated rats to that in intact rats, but, under periodic light, the decrease was smaller. Melatonin did not reverse the stronger effect of testosterone under constant light. The serum melatonin peak produced by the exogenous melatonin injection had a higher amplitude, shorter duration and earlier appearance than the physiological melatonin peak. Exogenous melatonin did not modify the physiological melatonin secretion, measured either as serum melatonin concentration or pineal melatonin content on the consecutive day.

We conclude that the increase in testosterone negative feedback sensitivity of castrated rats under constant light was not due to the absence of the nocturnal melatonin pulse.
\end{abstract}

Keywords: constant light; FSH; LH; melatonin; rat; testosterone

\section{Introduction}

Gonadal regression, which in seasonal breeders prevents pregnancy and delivery during an unfavourable time of the year, involves several reversible changes in the function of the gonadal axis. In hamsters, concentrations of gonadotrophins and prolactin as well as weight of testis and ovary decrease, while the content of hypothalamic luteinizing-hormone-releasing hormone (LHRH) increases (Steger et al., 1985). Shortening the daylength to $<12.5 \mathrm{~h}$ is the impulse that triggers the regression (Stetson \& Watson-Whitmyre, 1984).

Rats, which normally lack the photoperiodic response of gonadal regression, can be rendered photoperiodic by several manipulations. After, for example, olfactory bulbectomy (Nelson \& Zucker, 1981), administration of testosterone pellets (Vaughan et al., 1988) or neonatal androgenization, (Hoffmann et al., 1968), the testes of rats become smaller when the animals are kept under short photoperiod or constant darkness. It has been hypothesized that the mechanism of photoperiodicity also exists in rats, but is normally overruled by other regulatory mechanisms (Wallen \& Turek, 1981). If the pineal gland is removed the photoperiodic response of hamsters (Reiter, 1981) and photoperiodic rats (Wallen \& Turek, 1981) disappears.

Melatonin is the main product secreted by the pineal gland; secretion is high during the dark phase and very low during the light phase (Reiter, 1987). The secretion can be stopped by introducing light in the middle of the secretion period (Ebadi, 1984). Constant light prevents the circadian melatonin rhythm (Albers et al., 1981). Since pinealectomy prevents the photoperiodic response of gonadal regression (Reiter, 1981) and the short-day response can be accomplished by properly 
timed melatonin injections given under long-day conditions (Tamarkin et al., 1976), it is clear that melatonin can transfer the information of daylength from the retina to the gonadal axis.

The sensitivity to the negative feedback exerted by testosterone increases under short photoperiod in hamsters (Turek, 1977), and this effect is prevented by pinealectomy (Turek, 1979). It has been suggested that the increase in testosterone sensitivity would be at least one of the mechanisms that mediate the gonadal regression in seasonal breeders (Sisk \& Turek, 1982).

We have recently shown that under constant light testosterone decreases serum LH of castrated rats with a lower dose than under periodic light (Porkka-Heiskanen et al., 1989). In the present experiment we addressed the possible role of melatonin in this phenomenon. We hypothesized that the lack of melatonin rhythm under constant light had caused the increase in testosterone sensitivity, and that daily melatonin injections could prevent the effect.

The serum melatonin profile induced by our melatonin administration procedure was determined by measuring serum and pineal melatonin concentrations of rats after a single melatonin injection.

\section{Materials and Methods}

\section{Experiment 1}

The experimental animals were 98 male Wistar rats (age 3-4 months, weight $365 \pm 42 \mathrm{~g}$ ) from the colony of the Department of Physiology. Before the experiments, the rats were housed as described by Porkka-Heiskanen et al. (1989). Four weeks before the start of the experiments, 79 rats were castrated under methohexital anaesthesia ( $\left.90 \mathrm{mg} \mathrm{kg})^{-1}\right)$. For the experiment, the animals were divided into groups of 9-10 animals.

The conditions in the experimental room were: temperature $23-25^{\circ} \mathrm{C}, 60-75 \%$ humidity, and illumination produced by four cool white fluorescence tubes and measured at the level of cages $200-250 \mathrm{~lx}$. During the experiment, five groups were kept under periodic light ( $12 \mathrm{~h}$ light:12 h dark, lights on at 06:00 h) and five groups under constant light for one week. The rats received two injections (each of $0.1 \mathrm{ml}$ ) a day at 16:00 $\mathrm{h}$. The groups were: (i) intact rats receiving sesame oil and saline, (ii) castrated rats receiving sesame oil and saline, (iii) castrated rats receiving $125 \mu \mathrm{g}$ testosterone propionate and saline, (iv) castrated rats receiving $50 \mu \mathrm{g}$ melatonin and oil, and (v) castrated rats receiving $125 \mu \mathrm{g}$ testosterone and $50 \mu \mathrm{g}$ melatonin $\left(0 \cdot 151 \pm 0.019 \mu \mathrm{g} \mathrm{g}^{-1}\right)$. Testosterone propionate and melatonin were purchased from Sigma, St Louis, USA (Sigma T 1875 and Sigma M 5250, respectively). Testosterone propionate was dissolved in sesame oil at $50 \mu \mathrm{g}$ in $100 \mu \mathrm{l}$. Melatonin was dissolved in $100 \mu \mathrm{l}$ ethanol and diluted by saline to the final concentration $50 \mu \mathrm{g}$ in $100 \mu \mathrm{l}$. At the end of the experiment, the animals were decapitated at 10:00-11:00 h; the trunk blood was collected, left to clot for $60 \mathrm{~min}$ at room temperature and centrifuged for $30 \mathrm{~min}$ at $1000 \mathrm{~g}$. The serum was stored at $-20^{\circ} \mathrm{C}$ until the hormone measurements. The pineal and the pituitary glands were quickly removed, the anterior lobe of the pituitary gland was separated under a dissecting microscope, and the tissues were frozen on dry ice and stored at $-20^{\circ} \mathrm{C}$ until the hormone assays. The experiment was conducted in October-November.

\section{Experiment 2}

Before the experiments, the rats $(n=144$, male, age $3-4$ months, weight $386 \pm 39 \mathrm{~g})$ were housed as described above. One day before the experiment, the rats were moved to the experimental room which was illuminated by cool white fluorescence lamps from 06:00-18:00 h. The illumination measured at the level of cages was 300-350 lx. In the experiment the animals received a single s.c. injection $(0.1 \mathrm{ml})$ of either saline or $50 \mu \mathrm{g}$ melatonin $(0.127 \pm 0.013 \mu \mathrm{g}$ $\mathrm{g}^{-1}$ ) at 16:00 $\mathrm{h}$. Rats were decapitated in groups $30 \mathrm{~min}$ and $1,2,3,4,5,9,12$ and $15 \mathrm{~h}$ after the injection. The trunk blood was collected and stored as described above. The pineal gland was rapidly removed, frozen on dry ice and stored at $-20^{\circ} \mathrm{C}$ until the melatonin assay. The experiment was conducted in February-March.

\section{Hormone assays}

The gonadotrophins were measured by radioimmunoassay by reagents supplied by NIADDK, Baltimore, USA (reference preparations $\mathrm{rLH}-\mathrm{RP}-2$ and $\mathrm{rFSH}-\mathrm{RP}-2$ ). Serum assays were made directly from serum samples. The anterior lobe of the pituitary was homogenized in $1 \mathrm{ml}$ of phosphate buffer $(\mathrm{pH} 7.0)$ and centrifuged at $1000 \mathrm{~g}$ for $15 \mathrm{~min}$. The supernatants were diluted with phosphate buffer containing $1 \%$ bovine serum albumin. The dilutions were for LH 1:1000 and for follicle-stimulating hormone (FSH) 1:100. Serum and pituitary samples were measured in separate assays. The intra-assay variability for $\mathrm{LH}$ assays was $15-21 \%$ for samples from castrated rats and $8-11 \%$ for samples from intact rats; nonspecific binding was $4-5 \%$ and the detection limit $<0 \cdot 16 \mathrm{ng} \mathrm{ml}^{-1}$. The interassay variability of the samples for intact rats was $17 \%(n=10)$ and for castrated rats $9 \%(n=10)$. For FSH assays the intra-assay variability was $7-12 \%$, nonspecific binding $2 \%$, and detection limit $<2 \mathrm{ng} \mathrm{ml}^{-1}$. The interassay variability was at the serum concentration level of castrated rats $19 \%(n=13)$ and at the level of intact rats $16 \%(n=13)$. 
Serum melatonin concentration was measured as described by Laakso et al., (1990). Melatonin was extracted from the serum samples $(1 \mathrm{ml})$ with chloroform $(4 \mathrm{ml})$. The sample was evaporated to dryness and dissolved in $220 \mu l$ phosphate buffer. The hormone measurements were made from this concentrate in aliquots of $2 \times 100 \mu$. For the serum melatonin assay intra-assay variability was $13.6 \%$, detection limit $19.5 \mathrm{pg} \mathrm{ml}^{-1}$ and nonspecific binding $4.8 \%$. The interassay variability at the daytime concentration level of serum samples was $18 \cdot 2 \%$ and at the night time level $12 \cdot 3 \%(n=6)$.

The pineal glands were homogenized in $1 \mathrm{ml}$ phosphate buffer, centrifuged, and the supernatant was used in melatonin measurements as described in detail by Laakso et al., (1988). For the pineal melatonin assay intra-assay variability was $9 \cdot 8 \%$, the detection limit $19.5 \mathrm{pg} \mathrm{ml}^{-1}$ and nonspecific activity $5.5 \%$. The interassay variability at the concentration level of measured samples was $11 \%(n=6)$.

\section{Statistical analysis}

Data are expressed as means \pm standard errors of the mean (SEM). The measurements were subjected to one-way analysis of variance (ANOVA) (Siegel, 1956). Where the ANOVA indicated significant differences between the groups, the groups contributing to these differences were compared with the Tukey test. When $P<0.05$, the difference was accepted as statistically significant. Because of non-homogeneity of variances (revealed by Levene's test) the calculations were made with logarithmic transformed values.

\section{Results}

\section{Experiment 1}

Serum LH and FSH of castrated rats were significantly higher than those of intact rats under both lighting conditions (intact versus castrated $P<0 \cdot 01$, Figs 1a, b).

Serum LH of castrated rats was restored to the concentration of intact rats under constant light (intact versus testosterone not significant, Fig. 1a) but not under periodic light (intact versus testosterone $P<0.01$, Fig. 1a). Melatonin injections had no further effect on serum LH of testosteronetreated rats under either lighting condition (testosterone versus testosterone plus melatonin not significant Fig. 1a).

Serum FSH of castrated rats was restored only partially with testosterone injections (under both lighting conditions intact versus testosterone $P<0.01$, Fig. 1b). Melatonin did not modify the effect of testosterone (under both lighting conditions testosterone versus testosterone plus melatonin not significant). Serum FSH of melatonin-treated castrated rats kept under constant light was higher than that of castrated rats (castrated versus melatonin $P<0.01$, Fig. 1 b).

Pituitary $\mathrm{LH}$ of castrated rats was higher than that of intact rats under both lighting conditions (intact versus castrated $P<0.01$, Fig. Ic). None of the treatments had any further effect on pituitary $\mathrm{LH}$ of castrated rats under either lighting condition (Fig. lc).

Pituitary FSH of castrated rats was higher than that of intact rats under both lighting conditions (intact versus castrated $P<0.01$, Fig. 1d). Testosterone injections further increased pituitary FSH under periodic light (castrated versus testosterone-treated $P<0.05$ ), but not under constant light (castrated versus testosterone-treated not significant). Under constant light combined testosterone and melatonin injections increased pituitary FSH of castrated rats (castrated versus testosterone plus melatonin treated $P<0-05$ ). Melatonin injections alone had no effect on pituitary FSH under either lighting condition (castrated versus melatonin not significant).

Pineal melatonin content (at 10:00-11:00 h) was not affected by any of the treatments (data not shown).

\section{Experiment 2}

Concentrations of melatonin in serum of melatonin-injected ( $50 \mu \mathrm{g}$ melatonin s.c. at 16:00 h) rats stayed higher than the normal daytime serum concentrations (less than $25 \mathrm{pg} \mathrm{ml}^{-1}$ ) until 21:00 h (Fig. 2). At 07:00 h ( $15 \mathrm{~h}$ after the injection) the serum concentrations of melatonin-injected and control rats were similar (Fig. 2). Pineal melatonin content of melatonin injected rats did not differ from that of control rats at any of the time points (data not shown). The amplitude and 

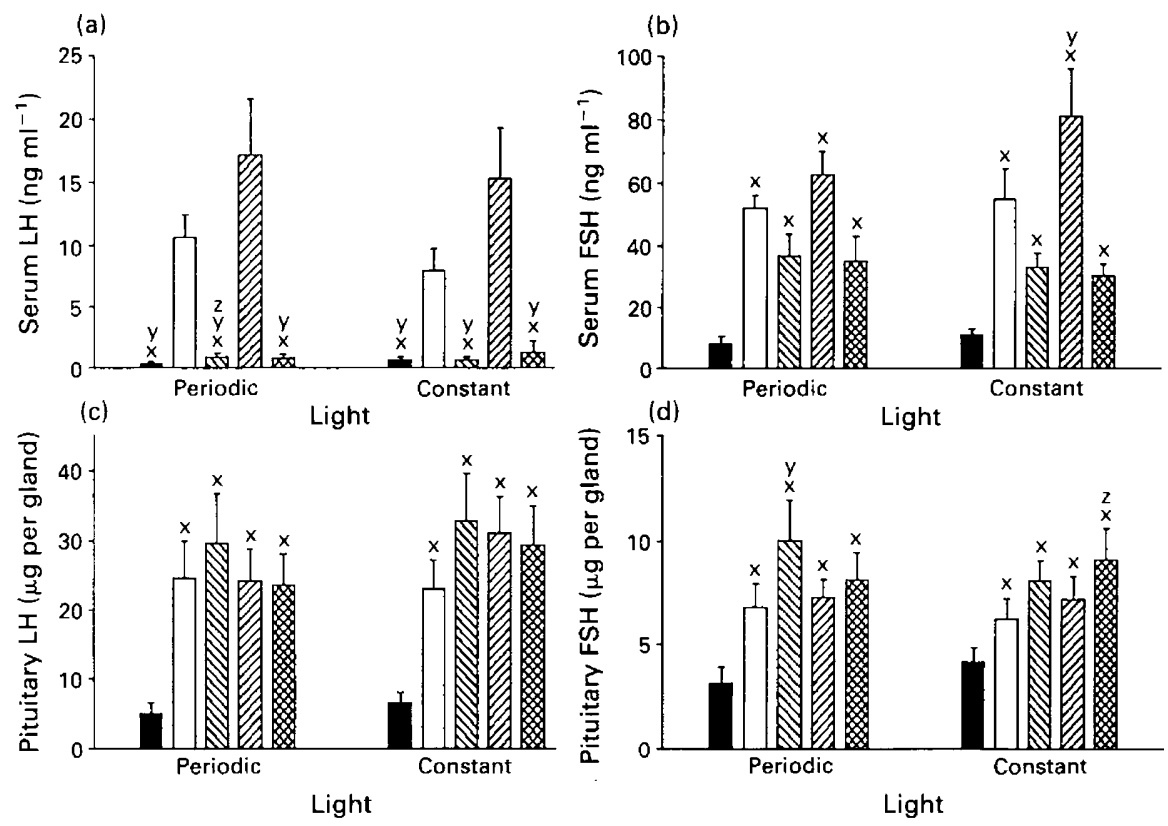

Fig. 1. Effect of daily s.c. testosterone and melatonin injections on (a) serum luteinizing hormone (LH), (b) serum follicle-stimulating hormone (FSH), (c) pituitary LH and (d) pituitary FSH concentrations of castrated rats kept under periodic or constant light for one week. Intact rats receiving sesame oil + saline ( $\mathbf{D})$; castrated rats receiving sesame oil + saline injection $(\square)$, castrated rats receiving $125 \mu \mathrm{g}$ testosterone propionate + saline (因), castrated rats receiving sesame oil $+50 \mu \mathrm{g}$ melatonin $(\square)$ and castrated rats receiving $125 \mu \mathrm{g}$ testosterone propionate and $50 \mu \mathrm{g}$ melatonin ( (a) x: significantly different from castrated rats $P<0.001$; y: significantly different from castrated rats treated with melatonin $P<0.001$; $z$ : significantly different from intact rats treated with testosterone $P<0.05$. (b) $\mathrm{x}$ : significantly different from intact rats $P<0.01$; y: significantly different from castrated rats $P<0.01$. (c) $x$ : significantly different from intact rats $P<0.01$. (d) $\mathrm{x}$ : significantly different from intact rats $P<0.01 ; \mathrm{y}$ : significantly different from castrated rats $P<0.05 ; \mathrm{z}$ : significantly different from castrated rats $P<0.05$.

timing (highest values between 01:00 and 04:00 h) of the nocturnal melatonin peaks were similar in melatonin injected and control rats.

\section{Discussion}

In the present study melatonin was introduced as a single injection in the afternoon each day for one week. It has been shown earlier that melatonin injections $(25-50 \mu \mathrm{g})$ given at 16:00 $\mathrm{h}$ can induce the short-day effect on the gonadal axis of hamsters (Tamarkin et al., 1976) and rats (Vaughan et al., 1988), indicating that the physiological effect of melatonin can be achieved by this dose and by this method of administration.

The serum melatonin profile produced by a single $50 \mu \mathrm{g}$ melatonin injection at $16: 00 \mathrm{~h}$ differed from that of the physiological nocturnal melatonin peak profile: the amplitude was higher and the peak appeared earlier in the evening. From the data measured under periodic light, the melatonin concentrations under constant light stayed high (more than $30 \mathrm{pg} \mathrm{ml}^{-1}$ ) from 16:00 $\mathrm{h}$ to $21: 00 \mathrm{~h}$ giving a duration of $5 \mathrm{~h}$ to the artificial melatonin peak. The possibility that some of these differences contributed to the result of the present experiment cannot be excluded. 


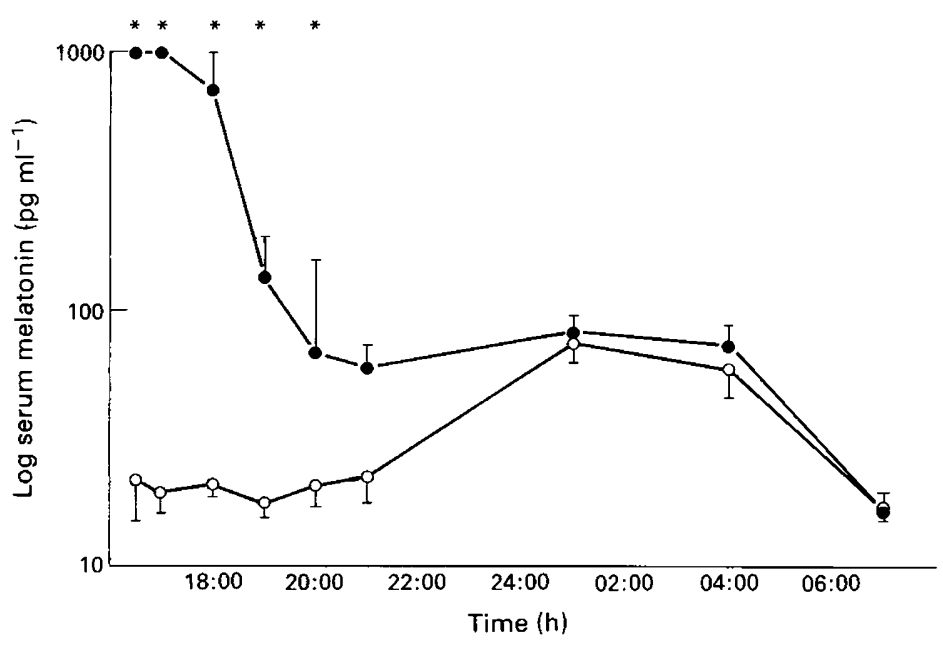

Fig. 2. Effect of a single s.c. injection of $(0) 50 \mu \mathrm{g}$ melatonin, $(O)$ saline at $16: 00 \mathrm{~h}$ on serum melatonin concentration of intact rats. *Significant differences between the two groups, Tukey test $P<0.01$.

The half-life of melatonin has been reported to be about $20 \mathrm{~min}$ in rats (Ozaki et al., 1976; Gibbs \& Vriend, 1981) and 13-17 min in hamsters (Vaughan et al., 1986; Brown et al., 1985). In one report the serum half-life of melatonin administered to hamsters was reported to have a very slow component of $25 \mathrm{~h}$ (Brown et al., 1985), indicating that repeated daily melatonin injections could lead to accumulation of melatonin in the body. The findings of this study agree well with the earlier ones, but do not support the finding that the half-life of melatonin has a second, long-lasting component (Brown et al., 1985).

Under constant light a low daily dose $(125 \mu \mathrm{g})$ of testosterone could decrease the serum LH concentration of castrated rats to the level of intact rats, whereas under periodic light a high dose $(250 \mu \mathrm{g})$ was needed (Porkka-Heiskanen et al., 1989). We wanted to determine whether this sensitization was due to lack of melatonin under constant light, since there is evidence that the increase in testosterone sensitivity associated with photoperiodicity is mediated by pineal melatonin (Ando et al., 1986; Vaughan et al., 1988). We have shown earlier that daily melatonin injections of $50 \mu \mathrm{g}$, administered at $09: 00 \mathrm{~h}$ or 16:00 h to intact or castrated rats do not modulate the secretion of gonadotrophins under periodic or constant light (Porkka-Heiskanen et al., 1990), but the possibility remained that melatonin might prevent the increase in testosterone sensitivity induced by constant light. The present finding that melatonin did not modify the effect of testosterone on serum LH suggests that the increase in testosterone sensitivity of rats is not related to the lack of the nocturnal melatonin peak. This finding further suggests that the mechanism of increase in testosterone sensitivity is different under constant light and under short photoperiod.

The results of the pituitary LH and FSH measurements agree with those measured earlier: under both lighting conditions pituitary gonadotrophin concentrations in the testosterone-treated groups were higher, suggesting that the testosterone treatment of castrated rats prevents the secretion of gonadotrophins from the pituitary gland (Porkka-Heiskanen et al., 1989). Melatonin modified the effect of testosterone in only one case: pituitary FSH in testosterone plus melatonin treated castrated rats kept under constant light was higher than in rats that were castrated only. However, there was not a statistically significant difference between the testosterone plus saline and the testosterone plus melatonin treated groups. In summary, melatonin did not modify the effect of testosterone on gonadotrophin concentrations either at the pituitary or serum concentration level. 
The results of this study do not support the hypothesis that the increase in testosterone sensitivity induced by constant light is directly caused by the absence of the nocturnal melatonin peak.

We thank S. Levo for her skilful assistance. The reagents for the hormone assays were provided by NIADDK and the anti-rabbit antibody used in precipitations was provided by $\mathbf{P}$. Männistö, University of Helsinki.

\section{References}

Albers, H.E., Gerall, A.A. \& Axelson, J.F. (1981) Circadian rhythm dissociation in the rat: effects of longterm constant illumination. Neuroscience Letters 25, 89-94.

Ando, S., Giacchetto, C., Canonaco, M., Aquila, S., Valenti, A., Beraldi, E., Piro, A. \& Dessi-Fulgheri, $S$. (1986) Effects of castration on androstenedione, testosterone and dihydrotestosterone plasma levels in adult male rats. Hormone Research 23, 122-127.

Brown, G.M., Seggie, J. \& Grota, L.J. (1985) Serum melatonin response to melatonin administration in the Syrian hamster. Neuroendocrinology 41, 31-35.

Ebadi, M. (1984) Regulation of the synthesis of melatonin and its significance to neuroendocrinology. In The Pineal Gland, pp. 1-37. Ed. R. J. Reiter. Raven Press, New York.

Gibbs, F.P. \& Vriend, J. (198I) The half-life of melatonin elimination from rat plasma. Endocrinology 109, 1796-1798.

Hoffmann, J., Kordon, C. \& Benoit, J. (1968) Effect of different photoperiods and binding on ovarian and testicular functions in normal and testosteronetreated rats. General and Comparative Endocrinology $10,109-118$.

Laakso, M-L., Porkka-Heiskanen, T., Alila, A., Peder, M. \& Johansson, G. (1988) Twenty-four-hour patterns of pineal melatonin and pituitary and plasma prolactin in male rats under natural and artificial lighting conditions. Neuroendocrinology 48, 308-313.

Laakso, M-L., Porkka-Heiskanen, T., Alila, A., Stenberg, D. \& Johansson, G. (1990) Correlation between salivary and serum melatonin: dependence on serum melatonin levels. Journal of Pineal Research 9, 39-50.

Nelson, R.J. \& Zucker, I. (1981) Photoperiodic control of reproduction in olfactory bulbectomized rats. Neuroendocrinology 32, 266-271.

Ozaki, Y., Lynch, H.J. \& Wurtman, R.J. (1976) Melatonin in rat pineal, plasma and urine: 24-hour rhythmicity and effect of chlorpromazine. Endocrinology 98, $1418-1424$

Porkka-Heiskanen, T., Laakso, M-L., Stenberg, D., Johansson, G. \& Peder, M. (1989) Lighting conditions affect testosterone feed-back sensitivity in castrated rats. Hormone Research 31, 184-189.

Porkka-Heiskanen, T., Laakso, M-L., Stenberg, D. \& Johansson, G. (1990) Daily melatonin injections have only minor effects on gonadotropins of intact or castrated male rats kept under constant or periodic light. Journal of Pineal Research 8, 221-228.
Reiter, R.J. (1981) Reproductive effects of the pineal gland and pineal indoles in the Syrian hamster and the albino rat. In The Pineal Gland, Vol. II. Reproductive Effects, pp. 46-8I. Ed. R. J. Reiter. CRC Press, Inc., Florida.

Reiter, R.J. (1987) The melatonin message: duration versus coincidence hypothesis. Life Sciences 40, 2119-2131.

Siegel, S. (1956) Nonparametric Statistics for the Behavioral Sciences McGraw-Hill Kogakusha, Ltd, Tokyo.

Sisk, C.L. \& Turek, F.W. (1982) Daily melatonin injections mimic the short day-induced increase in negative feed-back effects of testosterone on gonadotropin secretion in hamsters. Biology of Reproduction 27, 602-608.

Steger R.W., Matt, K. \& Bartke, A. (1985) Neuroendocrine regulation of seasonal reproductive activity in the male Golden hamster. Neuroscience and Biobehavioral Review 9, 191-201.

Stetson, M.H. \& Watson-Whitmyre, M. (1984) Physiology of the pineal and its hormone melatonin in annual reproduction in rodents. In The Pineal Gland, pp. 109-153. Ed. R. J. Reiter. Raven Press, New York.

Tamarkin, L., Westrom, W.K., Hamill, A.I. \& Goldman, B.D. (1976) Effect of melatonin on the reproductive system of male and female Syrian hamsters: a diurnal rhythm in sensitivity to melatonin. Endocrinology 99 , 1534-1541.

Turek, F.W. (1977) The interaction of the photoperiod and testosterone in regulating serum gonadotropin levels in castrated male hamsters. Endocrinology 101, $1210-1215$.

Turek, F.W.(1979) Role of the pineal gland in photoperiodinduced changes in hypothalamo-pituitary sensitivity to testosterone feedback in castrated male hamsters. Endocrinology 104, 636-640.

Vaughan, G.M., Mason, A.D. \& Reiter, R.J. (1986) Serum melatonin after single aqueous subcutaneous injection in Syrian hamsters. Neuroendocrinology 42, $124-127$.

Vaughan, M.K., Oaknin, S., Cozzi, B., Li, K. \& Reiter, R.J. (1988) Influence of melatonin on the testicular regression induced by subcutaneous testosterone pellets in male rats kept in long or short photoperiod. Journal of Reproduction and Fertility 82, 277-284.

Wallen, E. \& Turek, F.W. (1981) Photoperiodicity in the male albino laboratory rat. Nature 289, 402-404.

Received 2 September 1991 